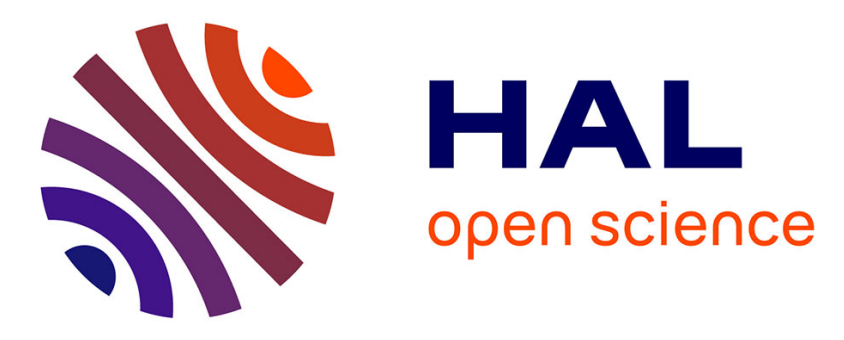

\title{
Study to assess the laryngeal and pharyngeal spread of topical local anaesthetic administered orally during general anaesthesia in children.
}

Richard Beringer, Noami Skeahan, Suzette Sheppard, Philip Ragg, Nick Martin, Ian Mckenzie, Andrew Davidson

\section{To cite this version:}

Richard Beringer, Noami Skeahan, Suzette Sheppard, Philip Ragg, Nick Martin, et al.. Study to assess the laryngeal and pharyngeal spread of topical local anaesthetic administered orally during general anaesthesia in children.. Pediatric Anesthesia, 2010, 20 (8), pp.757. 10.1111/j.14609592.2010.03353.x . hal-00560697

\section{HAL Id: hal-00560697 https://hal.science/hal-00560697}

Submitted on 29 Jan 2011

HAL is a multi-disciplinary open access archive for the deposit and dissemination of scientific research documents, whether they are published or not. The documents may come from teaching and research institutions in France or abroad, or from public or private research centers.
L'archive ouverte pluridisciplinaire HAL, est destinée au dépôt et à la diffusion de documents scientifiques de niveau recherche, publiés ou non, émanant des établissements d'enseignement et de recherche français ou étrangers, des laboratoires publics ou privés. 


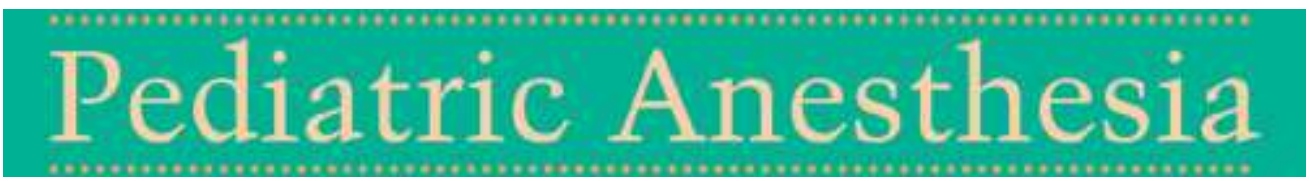

\section{Study to assess the laryngeal and pharyngeal spread of topical local anaesthetic administered orally during general anaesthesia in children.}

\begin{tabular}{|r|l|}
\hline Journal: & Pediatric Anesthesia \\
\hline Manuscript ID: & PAN-2009-0553.R1 \\
\hline Manuscript Type: & Original Paper \\
\hline Author: & $17-$ Submitted by the \\
\hline Complete List of Authors: & $\begin{array}{l}\text { Beringer, Richard; Bristol Royal Hospital for Children, Department } \\
\text { of Anaesthesia } \\
\text { Skeahan, Noami; Royal Children's Hospital, Department of } \\
\text { anaesthesia } \\
\text { Sheppard, Suzette; Murdoch Children's Research Institute, } \\
\text { Anaesthesia } \\
\text { Ragg, Philip; Royal Childrens Hospital, Melbourne, Anaesthesia } \\
\text { martin, nick; Royal Children's Hospital, Department of Anaesthesia } \\
\text { McKenzie, Ian; Royal Childrens Hospital, Melbourne, Anaesthesia } \\
\text { and Pain Management } \\
\text { Davidson, Andrew; Royal Children's Hospital, Department of } \\
\text { Anaesthesia; Murdoch Childrens Research Institute, Anaesthesia } \\
\text { Research }\end{array}$ \\
\hline Key Words: & \begin{tabular}{l} 
topical anesthesia , pediatric airway, lignocaine, local anaesthetic \\
\hline
\end{tabular} \\
\hline
\end{tabular}

\section{scholarONE" \\ Manuscript Central}




\section{Cover Letter}

Please consider the following paper for re-submission to Pediatric Anesthesia.

The enclosed manuscript has been read and approved by all authors, it is not under active consideration for publication elsewhere, has not been accepted for publication, nor has it been published in full or in part.

Yours faithfully,

R Beringer 


\section{Study to assess the laryngeal and pharyngeal spread of} topical local anaesthetic administered orally during general anaesthesia in children.

Richard Beringer*, Naomi Skeahan, Suzette Sheppard, Philip Ragg, Nick Martin, Ian McKenzie, Andrew Davidson

Department of Anaesthesia, Royal Children's Hospital, Melbourne, Australia

*Author for correspondence:

Consultant Anaesthetist, Department of Paediatric Anaesthesia, Bristol Royal Hospital for Children, 2 St Michaels Hill, Bristol, BS2 8BJ, UK.

Richard.beringer@uhbristol.nhs.uk

Running title: Topical anaesthesia of the paediatric airway 


\section{COVER SHEET: CO-AUTHOR DETAILS}

Naomi Skeahan: Paediatric anaesthesia fellow, Royal Children's Hospital, Melbourne, Australia.

Suzette Sheppard: Anaesthesia Research Project Officer, Murdoch Children's Research Institute, Melbourne, Australia

Philip Ragg, Nick Martin, Ian McKenzie and Andrew Davidson: Staff Anaesthetists, Royal Children's Hospital, Melbourne, Australia. 
Abstract:

Background: Topical local anaesthesia of the airway of anaesthetised children has many potential benefits. In our institution, lignocaine is topically instilled blindly into the back of the mouth with the expectation that it will come into contact with the larynx. The volume and method of application varies between clinicians. There is no published evidence to support the plausibility of this technique.

Aim: To determine whether this technique of instillation results in the local anaesthetic coming into contact with key laryngeal structures and whether this is influenced by volume or additional physical manoeuvres.

Methods/Materials: Sixty three healthy anaesthetised children between six months and 16 years old had lignocaine stained with methylene blue poured into the back of their mouths. The volume and subsequent physical manoeuvre were determined by randomisation. A blinded observer assessed staining of the vocal cords, epiglottis, vallecula and piriform fossae by direct laryngoscopy. Airway complications were recorded.

Results: Fifty three of the 63 children had complete staining of all four areas. Four children had one area unstained and all others had at least partial staining of all four structures. Nine children coughed following induction of anaesthesia. Coughing was more likely in children with incomplete staining $(p=0.03)$, low volume lignocaine $(p=0.003)$ and following a head lift $(p=0.02)$. 
Conclusion: Oral administration of lignocaine without use of a laryngoscope frequently results in widespread coverage of key laryngeal structures and may reduce the risk of coughing. 
Introduction:

Applying local anaesthetics topically to the airway of anaesthetised patients has many potential benefits such as: reducing the incidence of coughing and laryngospasm on induction or emergence from general anaesthesia (1-3), improving conditions for tracheal intubation in the absence of neuromuscular blockade (4), reducing the frequency of postoperative sore throat (5) and attenuation of the sympathetic nervous system response to intubation (6-9). Lignocaine is the most frequently used local anaesthetic agent for this purpose. It has been shown to be beneficial when used topically or systemically, but the evidence suggests a superior effect from topical use, with a lower total dose and lower systemic blood concentration (8).

These advantages must however be balanced by the potential risk to a child with a topically anaesthetised and unprotected airway, for example following extubation. Although there is no published literature to support a significant risk of aspiration in this situation, care must be taken with looking after a child with obtunded protective reflexes.

The most frequently described method for topical application of lignocaine is to spray it onto the laryngeal and tracheal mucosa under direct vision. An alternative technique has evolved in our institution, in which the local anaesthetic is blindly instilled into the back of the mouth, with the expectation that it will anaesthetise the hypopharynx and proximal laryngeal structures. This practice has some variations including use of different volumes of local 
anaesthetic as well as occasional use of additional procedures such as lifting the patient's head, or posterior depression of the larynx (dunking) with the intention of enhancing delivery of the solution to the desired anatomical structure. The advantages of this technique include simplicity, and avoidance of the need for laryngoscopy to allow application of the local anaesthetic. Laryngoscopy is a potent cause of sympathetic stimulation and is also associated with adverse reflexes such as laryngospasm and coughing. It is therefore best performed once the airway has been anaesthetised. Review of the published literature does not reveal any previous studies assessing the use of local anaesthetic in this way. There is therefore some uncertainty if this practice is clinically effective, or if it is even plausible that the local anaesthetic reaches the area of intended action.

In this study we added a dye (methylene blue) to the local anaesthetic and observed the degree of staining of the laryngeal structures. The purpose of this study was to gain evidence regarding the plausibility that this technique could anaesthetise the airway. In addition we wished to identify whether factors such as volume of local anaesthetic or additional physical manoeuvres influenced whether the local anaesthetic reached the intended site of action. By determining if the local anaesthetic does indeed reach the relevant structures, this could inform future practice, and provide the scientific plausibility for further study to examine the effectiveness of the technique in terms of relevant clinical outcomes. 


\title{
METHODS
}

\begin{abstract}
After obtaining parental consent and approval from the Human Research Ethics Committee at the Royal Children's Hospital in Melbourne, we recruited sixty three healthy children (ASA 1 or 2), aged between 6 months and 16 years, who were scheduled to undergo elective surgery for which they would require a tracheal tube. Children with a contraindication to the use of either of the study drugs, or an anticipated difficult laryngoscopy were excluded.
\end{abstract}

Children were stratified into five age groups ( 6 to 12 months; 1 to 2 years; 2 to four years; 4 to 8 years; and 8 to 16 years) and randomised to receive one of two volumes of lignocaine $(0.05$ or $0.15 \mathrm{ml} / \mathrm{kg}$ ), and one of three additional manoeuvres following application of the local anaesthetic (no additional manoeuvre; head lift; or laryngeal dunk). Head lift was performed by lifting the child's head until the chin touched the chest for three seconds and then returning it to the neutral position. Laryngeal dunk was performed by applying standard cricoid pressure for three seconds. Methylene blue was mixed with the lignocaine to act as a tissue stain. Two percent lignocaine was mixed with $1 \%$ methylene blue in a $9: 1$ ratio by volume, resulting in a solution containing 1.8 percent lignocaine and 0.1 percent methylene blue. A maximum volume of four millilitres was used.

The primary outcome measure was complete staining of four laryngeal structures: the vocal cords; piriform fossae; epiglottis; and vallecula. The secondary outcome measure was the frequency of airway complications after 
instillation of the dye up until the start of surgery, including: coughing; laryngospasm; oxygen desaturation (below 90 percent); and bradycardia (less than 80 percent of baseline rate).

All observations during the study were made by one of two principal investigators. The choice of anaesthetic technique was decided by the anaesthetist. Once the patient was anaesthetised, one investigator poured the predetermined volume of lignocaine/methylene blue into the back of the child's mouth over a few seconds using a syringe without needle and performed any additional manoeuvre required by randomisation. The facemask was then reapplied to the child's face and the child ventilated or allowed to breathe as normal. When the anaesthetist was satisfied that the child was adequately anaesthetised to allow intubation, the other blinded investigator perfomed standard direct laryngoscopy to assess the staining of the vocal cords, epiglottis, vallecula and piriform fossae. Staining was classified as complete, partial or unstained. The investigator or anaesthetist then inserted the tracheal tube and surgery commenced as normal. The degree of staining was recorded on a case report form along with demographic information, details of the anaesthetic technique and details of adverse events.

\section{Sample size and statistics}

This was a prospective, randomised, blinded, observational study. We initially intended to recruit a total of 120 patients. This would have resulted in 24 
children in each age group; 60 children for each volume of lignocaine; and 40 children for each additional manoeuvre. However, recruitment was slower than expected and after studying 63 children the principal investigator's rotation at the hospital came to an end. It was therefore decided that the study should be stopped at this stage. The analysis plan was to report the frequency of full staining in each combination group and depending on the spread of results, perform more sophisticated post-hoc analysis examining the difference between groups if possible. Such post-hoc analyses were performed using the Chi squared test, with Yates' correction for continuity when expected frequency was less than five. 


\section{RESULTS}

Sixty three children were recruited. More children were recruited from the older age groups, but otherwise the groups were well balanced (Table 1). Age ranged from seven months to 15 years, and weight ranged from seven to 109 kilograms. In the five different age groups (six to 12 months; 1 to 2 years; 2 to 4 years; 4 to 8 years and 8 to 16 years) there were $6 ; 6 ; 7 ; 21$ and 23 children respectively. In the low volume and high volume groups, there were 31 and 32 children respectively. For the different techniques (no additional technique; head lift and laryngeal dunk) there were $21 ; 20$; and 22 children respectively. No substantial differences were noted between the groups in terms of patient demographics or anaesthetic technique, including use of muscle relaxation. The time between instillation of solution and laryngoscopy ranged from 30 seconds to four minutes (median time one minute).

The primary outcome measure was complete staining of four laryngeal structures (vocal cords, piriform fossae, epiglottis and vallecula). Fifty three of the 63 subjects had complete staining of all four areas. Four children had one area unstained and all others had at least partial staining of the four structures. All children had complete staining of the piriform fossae. Eight children had only partial staining of the epiglottis, one child had an unstained vallecula and three children had no staining of the vocal cords. The details of the 10 children in whom there was incomplete staining are shown in Table 2. 
Quantitative analysis of the differences in the degree of staining between the different subgroups using the Chi squared test with Yates correction for continuity revealed no evidence for differences between: the five age groups $(p=0.9)$; the two different volumes $(p=0.3)$; or the use of additional techniques $(p=0.9)$

The secondary outcome measure was the frequency of adverse events during induction of anaesthesia (cough, laryngospasm and drop in oxygen saturation below 90 percent). Nine children coughed, two during intubation and seven following intubation. No children developed laryngospasm or bradycardia. Two children desaturated below 90 percent, although in both cases this was attributed to anaesthetic technique, not an airway complication. Details of the nine children who coughed are shown in Table 3. Coughing was more likely in children with incomplete staining (five of the 53 children with complete staining and in four of the 10 children with incomplete staining; risk ratio 0.24 ; $95 \%$ confidence intervals 0.08 to $0.7 ; p=0.03)$. All nine children who coughed had received the low volume of lignocaine $(p=0.003)$. Coughing occurred in seven children who had received a head lift, none who had received a laryngeal dunk and two patients in which no additional technique was used $(p=0.02)$.

Follow up of children after their procedure revealed no complications apart from temporary residual oropharyngeal staining. There were no reported episodes of aspiration or difficulty with drinking or eating in the postoperative period. 


\section{DISCUSSION}

These results demonstrate that oral administration of lignocaine without use of a laryngoscope frequently results in complete coverage of key laryngeal structures. Fifty three of 63 children had completely stained larynxes from this technique, and the other 10 children all had at least partial staining of the larynx.

The standard method of topically anaesthetising the airway is to spray local anaesthetic onto the larynx under direct vision using a laryngoscope. This might result in more frequent complete coverage than was demonstrated by this study, and therefore may be the technique of choice when local anaesthesia is absolutely necessary. However, laryngoscopy is not without risks and is associated with coughing, laryngospasm and regurgitation as well as stimulation of the sympathetic nervous system. A major potential benefit of the technique used in this study is to reduce the complications of laryngoscopy by providing anaesthesia before the laryngoscope comes into contact with the patient. Supplementary spraying of the trachea under direct vision may then be appropriate for some patients, such as those undergoing bronchoscopy. The observation that staining was extensive suggests it is plausible that the technique we use could be as effective as spraying under direct vision.

We wanted to identify whether factors such as volume of local anaesthetic or additional physical manoeuvres influenced whether the drug reached the 
intended site of action. No significant associations were observed with regards to staining of the larynx. However, the small numbers limit the power of this analysis.

Complications related to airway instrumentation during this study were a secondary outcome measure and relatively few in number, so it is difficult to draw firm conclusions. However, there was evidence for an association between both volume and technique, and coughing on induction. There was also evidence for an association between degree of staining and coughing. Coughing was more frequent in patients with incomplete coverage of the larynx, only occurred in patients who received the lower volume of lignocaine and was also associated with the use of head lift after administration of lignocaine. These findings would support using the higher volume of local anaesthetic and avoiding head lift in future practice.

The observation that topical lignocaine reduces risk of coughing is consistent with the findings of other investigators who have shown reduced frequency and severity of coughing for up to two hours following application of topical lignocaine (1). It seems plausible that by reducing the frequency of coughing, this technique may also reduce the frequency of more severe complications such as laryngospasm. Further study is necessary to determine whether this is the case.

The study has some limitations. The most significant is that staining does not necessarily equate with sufficient local anaesthesia to reduce reflex coughing 
or other responses to tracheal intubation. Although, as mentioned above we found evidence for some associations between staining and coughing, the anaesthetic conditions such as use of agent and depth of anaesthesia were not controlled at this period. These could influence any observed association. In order to design a study to assess the effect of topical local anaesthetic on adverse reflexes during anaesthesia, it would be necessary to standardise the anaesthetic technique and also the time between instillation of local anaesthetic and laryngoscopy.

There is a theoretical potential for physicochemical interactions between methylene blue and lignocaine which may have influenced the findings. Methylene blue is a weak acid ( $\mathrm{pH} 3$ to 4.5$)$ and may alter the lipid solubility of lignocaine and the detergent effect of methylene blue may have enhanced the spread of the mixture over mucus membranes.

The main disadvantage to using topical local anaesthetic within the airway is that persisting anaesthesia following extubation may make aspiration of pharyngeal contents more likely. There is little evidence in the literature to suggest that this is a significant problem, but it seems intuitive that the child with diminished protective reflexes may be at higher risk.

In summary, this study supports the plausibility of this technique for topical anaesthesia of the larynx of anaesthetised children. This supports the continued use of this technique and we plan to carry out further research based upon these findings to determine whether this local anaesthesia of the 
paediatric airway improves actual clinical outcomes compared to other techniques.

\section{ACKNOWLEDGEMENTS}

We would like to thank Associate Professor Donnath at the Murdoch

Children's Research Institute in Melbourne for her advice on study design and statistics. 


\section{REFERENCES}

1 Minogue SC, Ralph J, Lampa MJ. Laryngotracheal topicalization with lidocaine before intubation decreases the incidence of coughing on emergence from general anesthesia. Anesth Analg 2004; 99(4): 1253-7

2 Staffel JG, Weissler MC, Tyler EP et al. The prevention of postoperative stridor and laryngospasm with topical lidocaine. Arch Otolaryngol Head Neck Surg 1991; 117(10): 1123-8

3 Koç C, Kocaman F, Aygenç E et al. The use of preoperative lidocaine to prevent stridor and laryngospasm after tonsillectomy and adenoidectomy. Otolaryngol Head Neck Surg 1998; 118(6): 880-2.

4 Bülow K, Nielsen TG, Lund J. The effect of topical lignocaine on intubating conditions after propofol-alfentanil induction. Acta Anaesthesiol Scand 1996; 40(6): 752-6.

5 Tanaka Y, Nakayama T, Nishimori M et al. Lidocaine for preventing postoperative sore throat. Cochrane Database Syst Rev 2009; 8(3): CD004081.

6 Denlinger JK, Ellison N, Ominsky AJ. Effects of intratracheal lidocaine on circulatory responses to tracheal intubation. Anesthesiol 1974; 41(4): 409-12. 
7 Mostafa SM, Murthy BV, Barrett PJ et al. Comparison of the effects of topical lignocaine spray applied before or after induction of anaesthesia on the pressor response to direct laryngoscopy and intubation. Eur $J$ Anaesthesiol 1999;16(1): 7-10.

8 Hamaya Y, Dohi S. Differences in cardiovascular response to airway stimulation at different sites and blockade of the responses by lidocaine. Anesthesiol 2000; 93(1): 95-103.

$9 \quad$ Stoelting RK. Circulatory response to laryngoscopy and tracheal intubation with or without prior oropharyngeal viscous lidocaine. Anesth Analg 1977; 56(5): 618-21. 
Table 1

Randomisation details and degree of laryngeal staining

\begin{tabular}{|c|c|c|c|c|c|c|c|}
\hline \multicolumn{2}{|c|}{ Age } & \multicolumn{2}{|c|}{ Technique } & \multicolumn{2}{|c|}{ Volume } & \multicolumn{2}{|c|}{ Number of patients } \\
\hline category & $\begin{array}{c}\text { number } \\
\text { of } \\
\text { patients }\end{array}$ & category & $\begin{array}{c}\text { number } \\
\text { of } \\
\text { patients }\end{array}$ & $\begin{array}{l}\text { category } \\
(\mathrm{ml} / \mathrm{kg})\end{array}$ & $\begin{array}{c}\text { number } \\
\text { of } \\
\text { patients }\end{array}$ & $\begin{array}{l}\text { Incompletely } \\
\text { stained }\end{array}$ & $\begin{array}{l}\text { Completely } \\
\text { stained }\end{array}$ \\
\hline \multirow{7}{*}{$\begin{array}{c}6-12 \\
\text { months }\end{array}$} & & & \multirow{3}{*}{2} & & & & \\
\hline & \multirow{6}{*}{6} & \multirow{2}{*}{ None } & & 0.05 & 1 & & 1 \\
\hline & & & & 0.15 & 1 & & 1 \\
\hline & & \multirow{2}{*}{ Head lift } & \multirow{2}{*}{1} & 0.05 & 1 & & 1 \\
\hline & & & & 0.15 & 0 & & \\
\hline & & \multirow{2}{*}{$\begin{array}{l}\text { Laryngeal } \\
\text { dunk }\end{array}$} & \multirow{2}{*}{3} & 0.05 & 1 & & 1 \\
\hline & & & & 0.15 & 2 & & 2 \\
\hline \multirow{6}{*}{$\begin{array}{c}1-2 \\
\text { years }\end{array}$} & \multirow{6}{*}{6} & \multirow{2}{*}{ None } & \multirow{2}{*}{2} & 0.05 & 1 & 1 & \\
\hline & & & & 0.15 & 1 & & 1 \\
\hline & & \multirow{2}{*}{ Head lift } & \multirow{2}{*}{2} & 0.05 & 1 & & 1 \\
\hline & & & & 0.15 & 1 & & 1 \\
\hline & & \multirow{2}{*}{$\begin{array}{l}\text { Laryngeal } \\
\text { dunk }\end{array}$} & \multirow{2}{*}{2} & 0.05 & 1 & & 1 \\
\hline & & & & 0.15 & 1 & 1 & \\
\hline \multirow{6}{*}{$\begin{array}{l}2-4 \\
\text { years }\end{array}$} & \multirow{6}{*}{7} & \multirow{2}{*}{ None } & \multirow{2}{*}{1} & 0.05 & 0 & & \\
\hline & & & & 0.15 & 1 & 1 & \\
\hline & & \multirow{2}{*}{ Head lift } & \multirow{2}{*}{3} & 0.05 & 2 & 1 & 1 \\
\hline & & & & 0.15 & 1 & & 1 \\
\hline & & \multirow{2}{*}{$\begin{array}{l}\text { Laryngeal } \\
\text { dunk }\end{array}$} & \multirow{2}{*}{3} & 0.05 & 2 & & 2 \\
\hline & & & & 0.15 & 1 & & 1 \\
\hline \multirow{6}{*}{$\begin{array}{l}4-8 \\
\text { years }\end{array}$} & & None & 8 & 0.05 & 4 & & 4 \\
\hline & & None & 8 & 0.15 & 4 & & 4 \\
\hline & & & & 0.05 & 3 & & 3 \\
\hline & 21 & Head IItt & 6 & 0.15 & 3 & 1 & 2 \\
\hline & & Laryngeal & & 0.05 & 3 & 1 & 2 \\
\hline & & dunk & I & 0.15 & 4 & & 4 \\
\hline & & Nono & 8 & 0.05 & 4 & & 4 \\
\hline & & None & 8 & 0.15 & 4 & & 4 \\
\hline $8-16$ & 23 & Head lift & 8 & 0.05 & 4 & 2 & 2 \\
\hline years & 23 & Head IIt & 8 & 0.15 & 4 & & 4 \\
\hline & & Laryngeal & 7 & 0.05 & 3 & 2 & 1 \\
\hline & & dunk & 7 & 0.15 & 4 & & 4 \\
\hline
\end{tabular}




\section{Table 2}

Details of the 10 children with incomplete staining

\begin{tabular}{|cccccccc|}
\hline Patient & $\begin{array}{c}\text { Vocal } \\
\text { cords }\end{array}$ & $\begin{array}{c}\text { Piriform } \\
\text { Fossae }\end{array}$ & Epiglottis & Vallecula & $\begin{array}{c}\text { Age } \\
\text { (years })\end{array}$ & $\begin{array}{c}\text { Volume } \\
(\mathrm{mL} / \mathrm{Kg})\end{array}$ & Technique \\
\hline 1 & Complete & Complete & Partial & Complete & $4-8 \mathrm{yrs}$ & 0.15 & $\mathrm{HL}$ \\
2 & Complete & Complete & Partial & Complete & $4-8 \mathrm{yrs}$ & 0.05 & $\mathrm{LD}$ \\
3 & Complete & Complete & Partial & Complete & $8-16 \mathrm{yrs}$ & 0.05 & $\mathrm{HL}$ \\
4 & Complete & Complete & Partial & Complete & $4-8 \mathrm{yrs}$ & 0.05 & $\mathrm{HL}$ \\
5 & Complete & Complete & Partial & Complete & $8-16 \mathrm{yrs}$ & 0.05 & $\mathrm{HL}$ \\
6 & Complete & Complete & Partial & Complete & $4-8 \mathrm{yrs}$ & 0.15 & None \\
7 & Complete & Complete & Partial & Unstained & $2-4 \mathrm{yrs}$ & 0.15 & LD \\
8 & Unstained & Complete & Complete & Complete & $8-16 \mathrm{yrs}$ & 0.05 & LD \\
9 & Unstained & Complete & Complete & Complete & $1-2 \mathrm{yrs}$ & 0.05 & None \\
10 & Unstained & Complete & Partial & Complete & $8-16 \mathrm{yrs}$ & 0.05 & LD \\
\hline
\end{tabular}




\section{Table 3}

Details of the nine children who coughed

\begin{tabular}{|c|c|c|c|c|}
\hline Child & $\begin{array}{c}\text { Age } \\
\text { (years) }\end{array}$ & $\begin{array}{l}\text { Volume } \\
\text { (mL/Kg) }\end{array}$ & Staining & Technique \\
\hline 1 & 4 to 8 & 0.05 & complete & None \\
\hline 2 & 8 to 16 & 0.05 & incomplete & Head lift \\
\hline 3 & 4 to 8 & 0.05 & complete & Head lift \\
\hline 4 & 8 to 16 & 0.05 & complete & Head lift \\
\hline 5 & 2 to 4 & 0.05 & complete & Head lift \\
\hline 6 & 8 to 16 & 0.05 & complete & Head lift \\
\hline 7 & 1 to 2 & 0.05 & incomplete & None \\
\hline 8 & 4 to 8 & 0.05 & incomplete & head lift \\
\hline 9 & 8 to 16 & 0.05 & incomplete & head lift \\
\hline
\end{tabular}


SORT Statement 2001 - Checklist $A$

\section{Items to include when reporting a randomized trial}

\begin{tabular}{|c|c|c|c|}
\hline $\begin{array}{l}\text { PAPER SECTION } \\
\text { And topic }\end{array}$ & Item & Descriptor & $\begin{array}{l}\text { Reported on } \\
\text { Page \# }\end{array}$ \\
\hline TITLE \& ABSTRACT & 1 & $\begin{array}{l}\text { How participants were allocated to interventions (e.g., "random } \\
\text { allocation", "randomized", or "randomly assigned"). }\end{array}$ & $2,3-4$ \\
\hline $\begin{array}{l}\text { INTRODUCTION } \\
\text { Background }\end{array}$ & 2 & Scientific background and explanation of rationale. & $6-7$ \\
\hline $\begin{array}{l}\text { METHODS } \\
\text { Participants }\end{array}$ & 3 & $\begin{array}{l}\text { Eligibility criteria for participants and the settings and locations } \\
\text { where the data were collected. }\end{array}$ & 8 \\
\hline Interventions & 4 & $\begin{array}{l}\text { Precise details of the interventions intended for each group and } \\
\text { how and when they were actually administered. }\end{array}$ & 8 \\
\hline Objectives & 5 & Specific objectives and hypotheses. & $6-7$ \\
\hline Outcomes & 6 & $\begin{array}{l}\text { Clearly defined primary and secondary outcome measures and, } \\
\text { when applicable, any methods used to enhance the quality of } \\
\text { measurements (e.g., multiple observations, training of } \\
\text { assessors). }\end{array}$ & $8-9$ \\
\hline Sample size & 7 & $\begin{array}{l}\text { How sample size was determined and, when applicable, } \\
\text { explanation of any interim analyses and stopping rules. }\end{array}$ & $9-10$ \\
\hline $\begin{array}{l}\text { Randomization -- } \\
\text { Sequence generation }\end{array}$ & 8 & $\begin{array}{l}\text { Method used to generate the random allocation sequence, } \\
\text { including details of any restrictions (e.g., blocking, stratification) }\end{array}$ & 8 \\
\hline $\begin{array}{l}\text { Randomization -- } \\
\text { Allocation } \\
\text { concealment }\end{array}$ & 9 & $\begin{array}{l}\text { Method used to implement the random allocation sequence (e.g., } \\
\text { numbered containers or central telephone), clarifying whether the } \\
\text { sequence was concealed until interventions were assigned. }\end{array}$ & \\
\hline $\begin{array}{l}\text { Randomization -- } \\
\text { Implementation }\end{array}$ & 10 & $\begin{array}{l}\text { Who generated the allocation sequence, who enrolled } \\
\text { participants, and who assigned participants to their groups. }\end{array}$ & 9 \\
\hline Blinding (masking) & 11 & $\begin{array}{l}\text { Whether or not participants, those administering the } \\
\text { interventions, and those assessing the outcomes were blinded to } \\
\text { group assignment. If done, how the success of blinding was } \\
\text { evaluated. }\end{array}$ & 9 \\
\hline Statistical methods & 12 & $\begin{array}{l}\text { Statistical methods used to compare groups for primary } \\
\text { outcome(s); Methods for additional analyses, such as subgroup } \\
\text { analyses and adjusted analyses. }\end{array}$ & $9-10$ \\
\hline $\begin{array}{c}\text { RESULTS } \\
\text { Participant flow }\end{array}$ & 13 & $\begin{array}{l}\text { Flow of participants through each stage (a diagram is strongly } \\
\text { recommended). Specifically, for each group report the numbers } \\
\text { of participants randomly assigned, receiving intended treatment, } \\
\text { completing the study protocol, and analyzed for the primary } \\
\text { outcome. Describe protocol deviations from study as planned, } \\
\text { together with reasons. }\end{array}$ & \\
\hline Recruitment & 14 & Dates defining the periods of recruitment and follow-up. & \\
\hline Baseline data & 15 & Baseline demographic and clinical characteristics of each group. & \\
\hline Numbers analyzed & 16 & $\begin{array}{l}\text { Number of participants (denominator) in each group included in } \\
\text { each analysis and whether the analysis was by "intention-to- } \\
\text { treat". State the results in absolute numbers when feasible (e.g., } \\
10 / 20, \text { not } 50 \%) \text {. }\end{array}$ & \\
\hline $\begin{array}{l}\text { Outcomes and } \\
\text { estimation }\end{array}$ & 17 & $\begin{array}{l}\text { For each primary and secondary outcome, a summary of results } \\
\text { for each group, and the estimated effect size and its precision } \\
\text { (e.g., } 95 \% \text { confidence interval). }\end{array}$ & \\
\hline Ancillary analyses & 18 & $\begin{array}{l}\text { Address multiplicity by reporting any other analyses performed, } \\
\text { including subgroup analyses and adjusted analyses, indicating } \\
\text { those pre-specified and those exploratory. }\end{array}$ & \\
\hline Adverse events & 19 & $\begin{array}{l}\text { All important adverse events or side effects in each intervention } \\
\text { group. }\end{array}$ & \\
\hline $\begin{array}{l}\text { DISCUSSION } \\
\text { Interpretation }\end{array}$ & 20 & $\begin{array}{l}\text { Interpretation of the results, taking into account study } \\
\text { hypotheses, sources of potential bias or imprecision and the } \\
\text { dangers associated with multiplicity of analyses and outcomes. }\end{array}$ & \\
\hline Generalizability & 21 & Generalizability (external validity) of the trial findings. & \\
\hline Overall evidence & 22 & $\begin{array}{l}\text { General interpretation of the results in the context of current } \\
\text { evidence. }\end{array}$ & \\
\hline
\end{tabular}


74 Assessed for eligibility

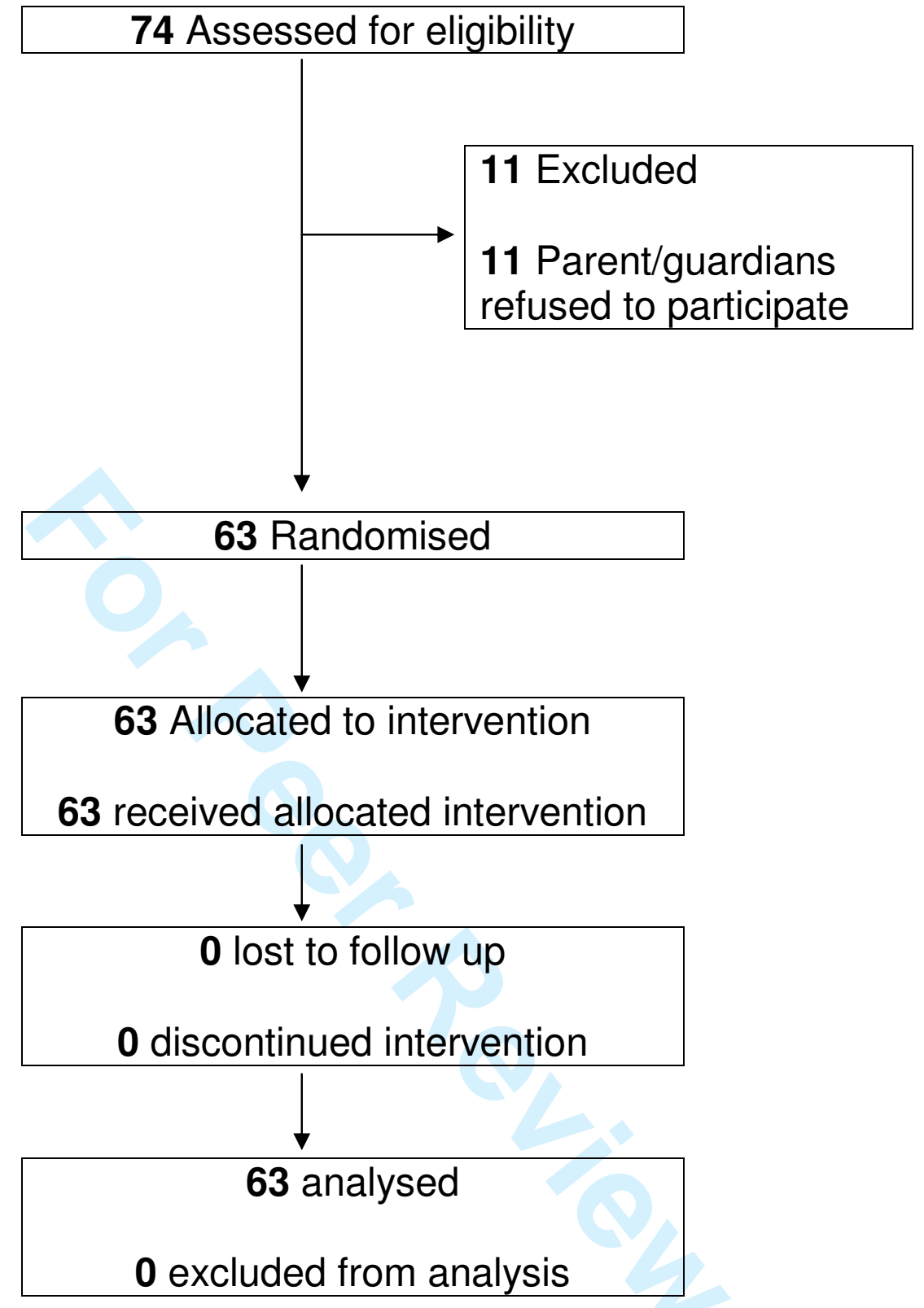

